\title{
INCREASING ELECTRICITY SELF-CONSUMPTION IN RESIDENTIAL BUILDINGS BY ELECTRICITY-TO-HEAT CONVERSION AND STORAGE
}

Erkki JÕGI, Estonian University of Life Sciences, Institute of Technology, Chair of Energy Application Engineering, Fr.R. Kreutzwaldi 56, 51014 Tartu, Estonia, erkki.jogi@emu.ee

Alo ALLIK, Estonian University of Life Sciences, Institute of Technology, Chair of Energy Application Engineering, Fr.R. Kreutzwaldi 56, 51014 Tartu, Estonia, alo.allik@emu.ee

Hardi HÕIMOJA, Estonian University of Life Sciences, Institute of Technology, Chair of Energy Application Engineering, Fr.R. Kreutzwaldi 56, 51014 Tartu, Estonia, hardi.hoimoja@emu.ee

Tõnis PEETS, Estonian University of Life Sciences, Institute of Technology, Chair of Energy Application Engineering, Fr.R. Kreutzwaldi 56, 51014 Tartu, Estonia, tonis.peets@emu.ee

Heino PIHLAP, Estonian University of Life Sciences, Institute of Technology, Chair of Energy Application Engineering, Fr.R. Kreutzwaldi 56, 51014 Tartu, Estonia, heino.pihlap@student.emu.ee

Mart HOVI, Estonian University of Life Sciences, Institute of Technology, Chair of Energy Application Engineering, Fr.R. Kreutzwaldi 56, 51014 Tartu, Estonia, mart.hovi@emu.ee

Eve ARUVEE, Estonian University of Life Sciences, Institute of Technology, Department of Applied Mathematics and Physics, Fr.R. Kreutzwaldi 56, 51014 Tartu, Estonia, eve.aruvee@emu.ee

Janar KALDER, Estonian University of Life Sciences, Institute of Technology, Chair of Energy Application Engineering, Fr.R. Kreutzwaldi 56, 51014 Tartu, Estonia, janar.kalder@emu.ee

Maido MÄRSS, Eesti Energia Ldt., Department of Renwable Energy, PV Project manager, Lelle 22, 11318 Tallinn, Estonia, maido.marss@energia.ee

Jaanus UIGA, Ministry of Economic Affairs and Communications, Energy Department, Suur-Ameerika 1, Tallinn 10122, Estonia, jaanus.uiga@mkm.ee

Andres ANNUK, Estonian University of Life Sciences, Institute of Technology, Chair of Energy Application Engineering, Fr.R. Kreutzwaldi 56, 51014 Tartu, Estonia, andres.annuk@emu.ee (corresponding author)

The current paper addresses energy storage issues in residential buildings with the objective of increasing direct consumption. The building, connected to an utility grid, is supplied by a micro wind turbine and PV panels. The utility grid itself acts as an energy buffer. Only nonshiftable loads (white goods, TV etc.) and electric water heating are taken into account. The studied configuration comprises two cascaded heating boilers, one of them preheating boiler. The annual electricity production of the micro wind turbine and PV panels is chosen to cover the hot water demand and nonshiftable loads inside the building with 70/30 ratio in favour of the wind energy. During the experiments, the generation graphs' shaving levels vary between 0 and $100 \%$, with peak energy diverted into a preheating boiler and the remaining part fed into the main boiler. The proposed solution allows increasing locally consumed energy share, as the energy of stochastic peaks is stored and used on later demand. The locally consumed energy is expressed by the cover factor, its increase possibilities are studied in main text. Calculations are based on 5- minute time series. The applied algorithm follows the amount of heat in the main and preheating boiler, including also incoming and outgoing energies. The cover factor cannot be increased without restrictions. Too high shaving levels bring along problem of removing excess heat from the preheating boiler. The allowed drain loss is taken as $10 \%$ of annual boiler energy balance. The presumed growth of the cover factor at preheating boiler volume of 1601 instead of 801 is at least $8 \%$. with the main boiler sized as before.

Keywords: cover factor, demand response, domestic hot water, load shifting, solar energy, wind energy

\section{INTRODUCTION}

Amidst all renewable energy sources, the wind and solar ones have the longest historical records with increasing expansion pace during the last decade (Kaldellis and Zafirakis, 2011). The rapid growth of the wind and solar share in the overall energy mix is mainly related to large installations in form of generation parks. As for micro wind and solar power, the growth is encouraged by the EU requirements on net zero-energy buildings (Kaldellis and Zafirakis, 2011). The largely fluctuating and unpredictible power output of wind and solar installations is a common knowledge (Allik and Annuk, 2016; Tabone and Callaway, 2014; Ming et al., 2015). To alleviate the stochastic character of the described primary energy sources, several local demand side management (DSM) approaches are applied. The application of heat pumps is one of the most widespread ones, discussed in the current paper as well (Vanhoudt et al., 2014; Elkinton et al.,

Copyright (C) 2017 The Authors. Published by Aleksandras Stulginskis University. This is an open-access article distributed under the terms of the Creative Commons Attribution License (CC-BY 4.0), which permits unrestricted use, distribution, and reproduction in any medium, provided the original author and source are credited. 
2009). Other peak shaving possibilities of stochastic power generation graphs include batteries (Iqbal, 2004; Rahmoun, et al., 2016; Rosin et al., 2012), pumped hydro storage (Zoss et al., 2015), direct current (DC) loads (Gabbar and Abdelsalam, 2014; Loh et al., 2014), enhanced wind and solar generation forecast (Aguilar et al., 2014) or compressed air storage (Ciocan et al., 2015). In principle, there exist two types of measures to alleviate stochastics of the primary sources, either to store the produced energy partially or fully and reuse it later, or to increase the share of direct demand by applying different methods. Both of them have their disadvantages. The article combines both approaches with additional heating boiler alleviating the stochastics of wind and solar inputs (Allik et al., 2016; Pourmousavi et al., 2014), optionally load shifting can be applied (Hassanzadeh et al., 2017). The additional preheating boiler stores the peaks of the wind and solar generation graphs. During the simulations, both (wind and solar) generation graphs were shaved at different levels between 0 to $100 \%$ of the rated power, where $0 \%$ describes the situation when all the incoming energy is fed into a preheating boiler and at $100 \%$, there is no peak shaving at all. Both the wind and solar generation graphs are shaved similarly. The study aims studying the possibilities of increasing the supply cover factor in a residential building with two heating boilers installed as energy storage units. Volume of the main boiler remains the same, but one can vary the volume of the preheating boiler and find how does it act upon the cover factor.

\section{MATERIALS AND METHODS}

The wind turbine and PV panels are located on a building roof at $58^{\circ} 23^{\prime} 19^{\prime \prime}$ N, $26^{\circ} 41^{\prime} 37^{\prime \prime}$ E. The network analyzer Janitza UMG 605 (Janitza...,2017) with current transformers Circutor P2 TC5 M70312 provides the data acquisition (Circuator..., 2017). The time series begins with December, 2015 and ends with November, 2016. The production graphs are shaved at the 5 minute averaged actual power levels, whereas the succeeding calculations are based on the corresponding 5 minute sum energy portions.

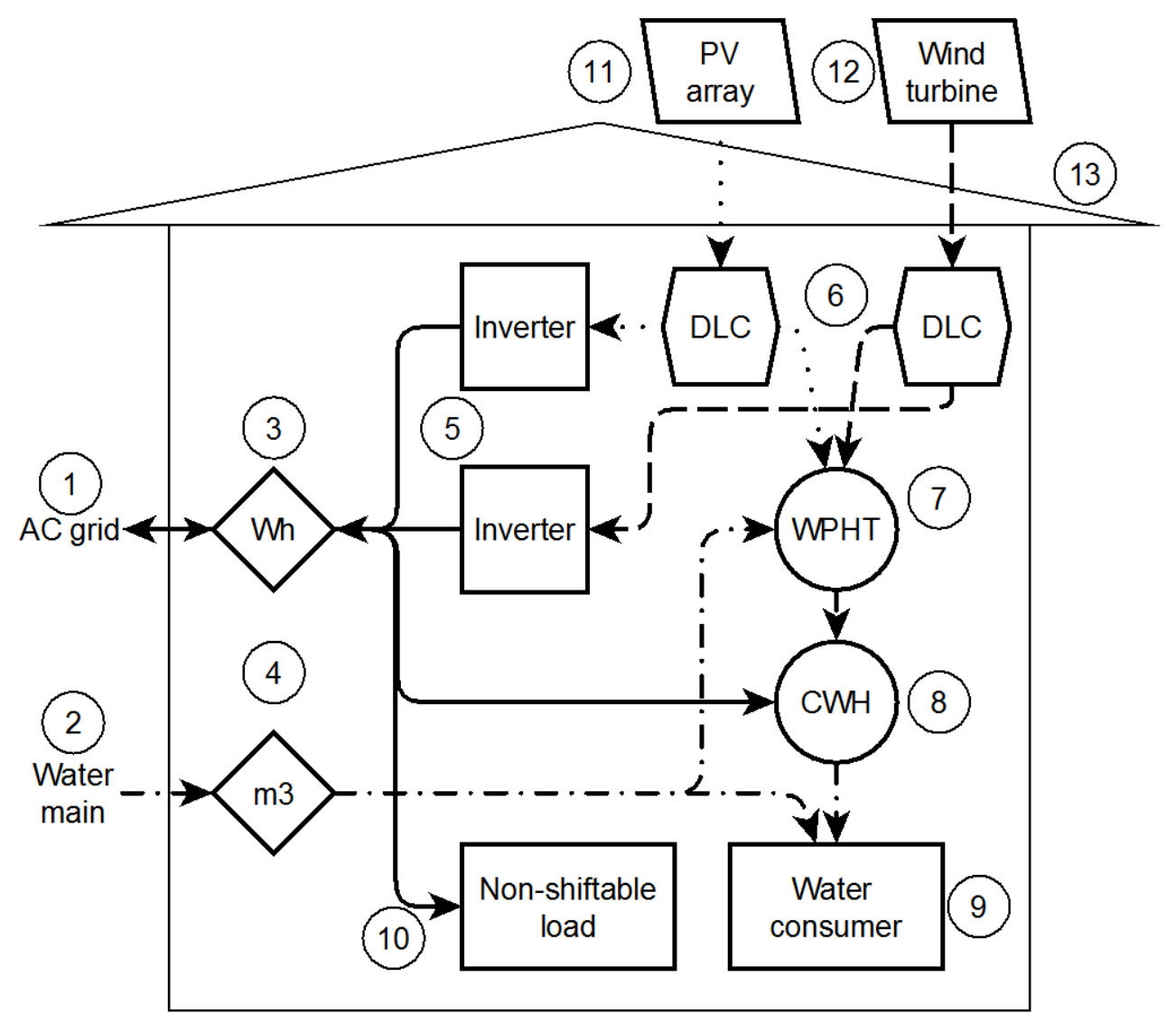

Figure 1. With two boiler equipped energy storage principal solution scheme

Where: Solid line - AC flow, dashed line - variable frequency AC flow, dash-dot line - water flow, dotted line - DC flow, $1-\mathrm{AC}$ grid, $2-$ Water main line, 3 - bidirectional electrical energy meter, 4 - water meter, 5 - inverters for PV array and wind turbine, 6 - dump load controller (DLC), 7 - water pre-heater boiler (WPHT), 8 - conventional water heater (CWH), 9 - Hot and cold water consumer, 10 - non-shiftable loads (HVAC, TV, etc), 11 PV panels, 12 - Wind turbine, 13 - Near-Zero Energy Building.

Fig. 1 explains a solution with two equally sized boilers, where the first, the preheating one acts as a dump load, absorbing the wind turbine and solar panel shaved peaks. Both the wind turbine and the solar panel have their own heating elements. If the preheating boiler is not capable of absorbing the whole shaved energy from the generating units, an emergency valve opens and drains part of the hot water. The main boiler is meant to accumulate the remaining energy below the generation units' shaving levels and can operate even without the preheating boiler. 
The given research discusses a typical household electricity load graph. Two load types are observed: non-shiftable (white goods, TV etc.) and boiler loads. Instead of a single boiler, two equally sized boilers are applied. The household's annual electricity consumption is $3473 \mathrm{kWh}$, which remains between Estonian $(2957 \mathrm{kWh} /$ year) and European Union average values $(3601 \mathrm{kWh} /$ year) (World..., 2015). The nonshiftable load counted $1632 \mathrm{kWh} / \mathrm{y}$. The data were initially measured and later brought to scale. The boiler volume selection is based on literature (Allik etc., 2016). Nevertheless, both boilers were chosen with 801 volume, in the preheating boiler there was a double $2 \mathrm{~kW}$ heating element, one to absorb excess power from the wind turbine and the other from the solar panel. The boiler energy capacity was taken $5.4 \mathrm{kWh}$. The boilers are designed to consume $1840 \mathrm{kWh} / \mathrm{y}$, i.e. $53 \%$ of the total consumption. The boiler load graphs are based on real measurements. For comparison, in Germany the electric boilers consume $13 \%$ and in the United Kingdom, $20 \%$ of a household's electricity (Ferrantelli etc., 2017). The calculations do not include the electricity for room heating purposes. The utility grid acts as an energy buffer absorbing the proficiencies and covering the deficiencies.

The current simulation involves following production devices: horizontal axis, $3.5 \mathrm{~kW}$, passive yaw control permanent magnet generator (Sonkyo..., 2015), with SMA Sunny Boy 3600TL inverter (SMA..., 2017) and 2.5 kW PV array (DelSolar $250 \mathrm{~W}$ D6P250B3A) (Yingli..., 2017), orientated towards South with $40^{\circ}$ elevation. A $2.75 \mathrm{~kW}$ grid tie inverter (SOLIVIA 2.5 EU G3) (SMA..., 2017) is used for DC/AC conversion.

The generation graphs of both the wind turbines and solar panels are based on real measured data and scaled accordingly. The wind turbine is scaled to $5.84 \mathrm{~kW}$ and the solar panel set to $1.02 \mathrm{~kW}$. The power ratio is chosen on the basis of a 70/30 annual wind/solar energy mix in favour of the wind energy (Caralis et al., 2011; Annuk et al., 2011; Annuk et al., 2013) ). Both generation graphs are shaved on the same level. The wind turbine is located in urban conditions, causing a low capacity factor of $C F=0.06$ and for solar panels, the value is an Estonian average $C F=0.11$.

The cover factors (Allik et al., 2016; Baetens et al., 2012) express both locally produced and directly consumed power shares:

$$
Y_{S}=\frac{\int_{t_{0}}^{t_{1}} P_{D} d t+\int_{t_{1}}^{t_{2}} P_{S} d t}{\int_{t_{0}}^{t_{2}} P_{S} d t} \quad Y_{D}=\frac{\int_{t_{0}}^{t_{1}} P_{D} d t+\int_{t_{1}}^{t_{2}} P_{S} d t}{\int_{t_{0}}^{t_{2}} P_{D} d t}
$$

where $P_{S}$ is the local power supply and $P_{D}$ the local power demand. The time when $P_{D}(t) \leq P_{S}(t)$ is denoted as $t_{0} \ldots t_{1}$, and $t_{1} \ldots t_{2}$ is the time when $P_{D}(t)>P_{S}(t)$. The supply cover factor is a measure for the self-consumption of locally produced renewable energy (Vanhoudt et al., 2014). Similarly, the demand cover factor is defined as 'the ratio to which the energy demand is covered by the local supply' and indicates the 'self-generation' (Vanhoudt et al., 2014).

According to the prior work (Annuk et al., 2017), the cover factor can be increased under given circumstances up to $Y_{S}=Y_{D}=0.6$ in case when generation graphs are shaved at $25 \%$ level. Although higher cover factor values are achievable, the limiting factor is an increased energy drain loss to avoid the overheating hazard.

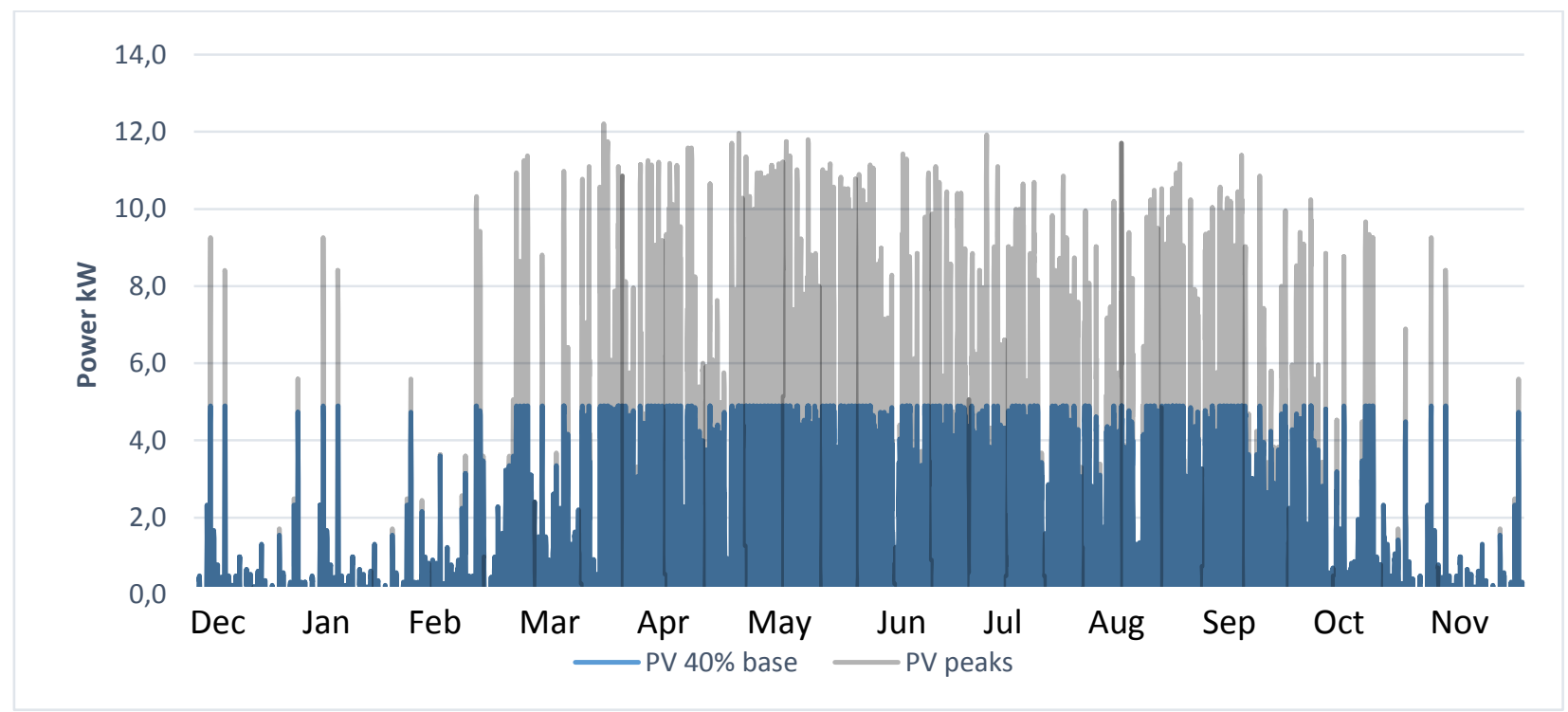

Figure 2. Sample of annual hour-based generation graphs with $40 \%$ shaving level for PV base and peak generation

Fig. 2 exhibits annual hour-based PV generation graphs, showing both the base generation shaved at $40 \%$ level and the shaved peaks. If add here wind turbine production graph, when they are balancing together some extent. In summer time is excess PV electricity, but wind energy production is little bit less intensive in this time. The drain losses, caused by excess overheated water diverted into the drain, are assumed to be equal to the heat dissipation into the surrounding environment, i.e. $10 \%$ (Pournousavi et al., 2014) of the boiler's annual energy balance. The exact energy capacity calculated from the boiler volume is $5.05 \mathrm{kWh}$, however $5.4 \mathrm{kWh}$ has been taken as the base value. While varying the preheating boiler volume at constant main boiler energy capacity from initial $5.4 \mathrm{kWh}$ to 2.5 -fold value the cover factor is assumed to change. Upsizing the main boiler would bring along additional losses into the surrounding ambient, as the heat exchange surface grows as well. The main boiler temperature must 
remain constant, additional energy is taken from the utility grid when needed. Upsizing the preheating boiler does not result in more losses, as the passing energy remains the same. The calculations are based on the MatLab software suite.

\section{RESULTS AND DISCUSSION}

The section provides an analysis overview of the conception and solution proposed in the previous section. Fig. 3 brings into evidence the impact of different preheating boiler volumes on the cover factor, which rises up to 0.7 .

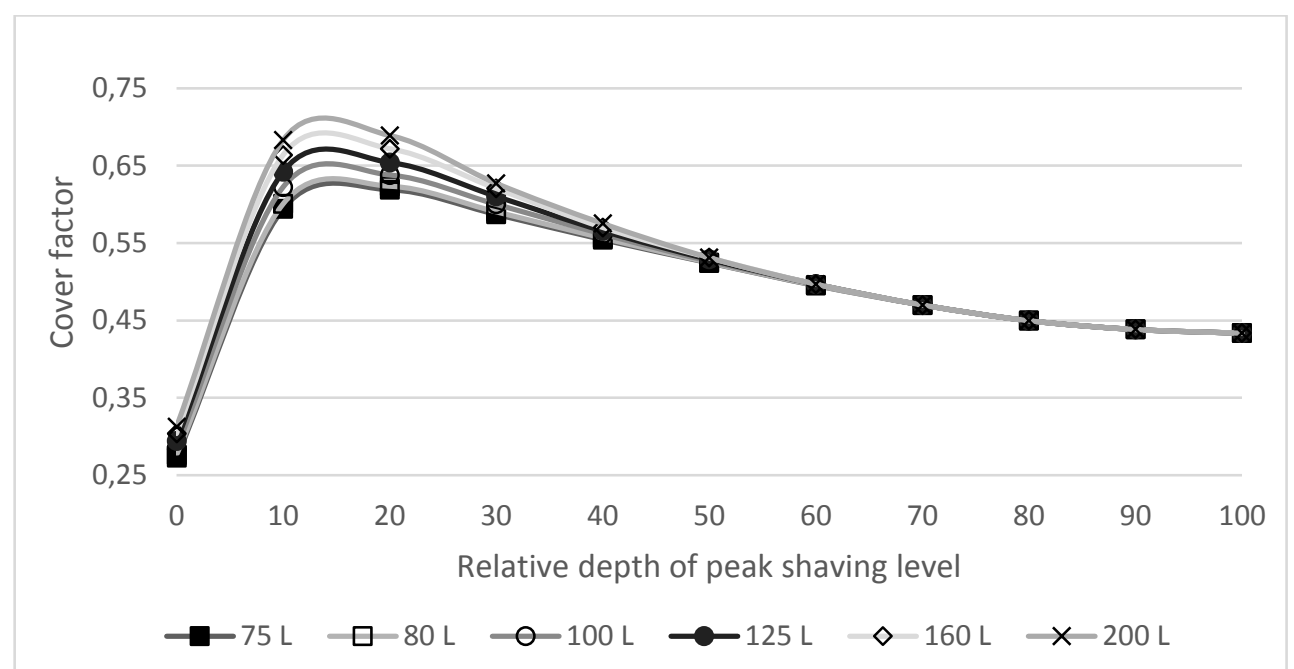

Figure 3. Cover factor at different generation graph shaving levels at different preheating boiler capacities

As mentioned in the previous section, maximal cover factor values are not applicable, as they cause additional losses in form of excess energy diverted into drain.

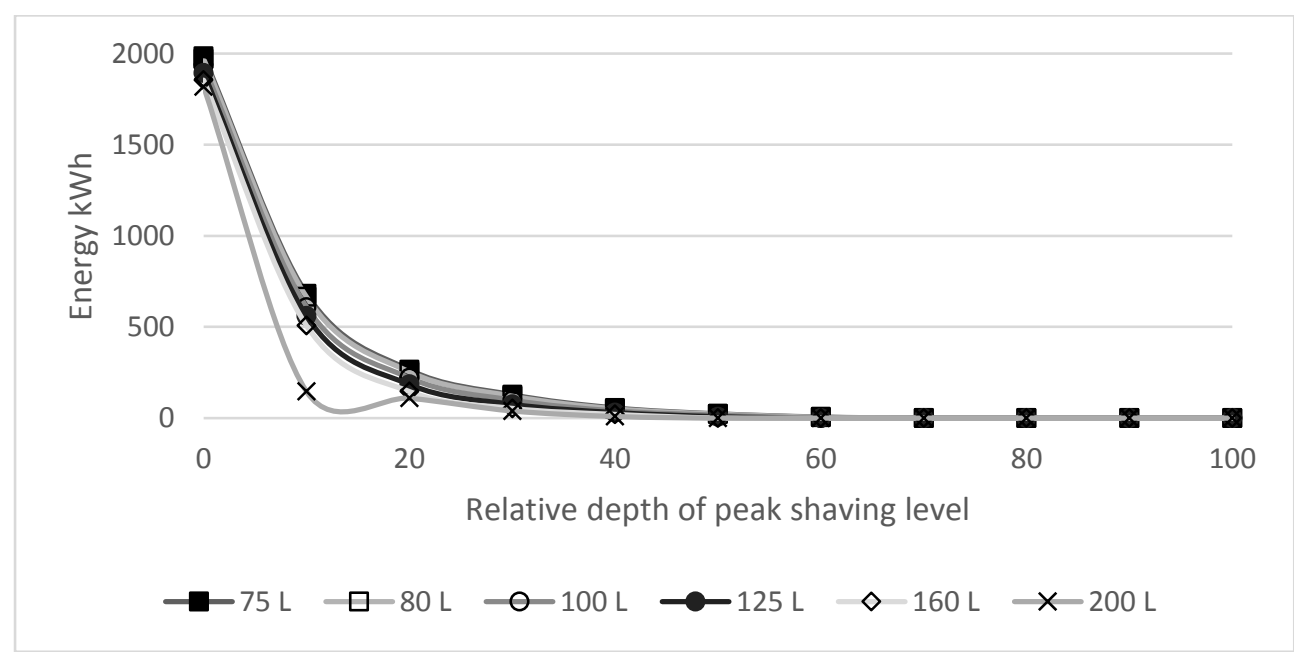

Figure 4. Drain losses of the preheating boiler in dependence of shaving levels at different volumes

At drain losses limited to $10 \%$ of the boiler's energy balance, i.e $184 \mathrm{kWh} / \mathrm{y}$, the cover factors are shown in Table 1. At double boiler volume, i.e. at 160 , the cover factor becomes equal to 0.68 .

Table 1. Cover factor values at preheating boiler drain losses limited to $184 \mathrm{kWh} / \mathrm{y}$

\begin{tabular}{|c|c|c|c|}
\hline Boiler volume, 1 & Boiler heat capacity, $\mathrm{kWh}$ & Cover factor & $\begin{array}{c}\text { Shaving level of generation } \\
\text { charts, } \%\end{array}$ \\
\hline 75 & 5.05 & 0.6 & 25 \\
\hline 80 & 5.4 & 0.6 & 25 \\
\hline 100 & 6.75 & 0.63 & 22 \\
\hline 125 & 8.44 & 0.65 & 18 \\
\hline 160 & 10.8 & 0.68 & 10 \\
\hline 200 & 13.5 & 0.68 & - \\
\hline 240 & 16.2 & 0.7 & \\
\hline
\end{tabular}

Further upsizing is not advantageous, as the cover factor gain is negligible and therefore not cost effective. In the other hand, at greater boiler volumes, the possibility of overheating and drain losses becomes less. The solution of 
different shaving levels for wind turbine and solar panel generation graphs is yet to be checked. The processes should be evaluated in windier locations as well.

\section{CONCLUSION}

The electricity-to-heat energy conversion and storage contribute to more self-consumption in a residential building. Apart from the input power shaving levels, the self-consumption, expressed by the cover factor, is influenced by the heat storage capacity, i.e. the boiler volume. The conversion of electricity to heat is in this case irreversible - the heat cannot be converted to electricity. The self-consumption could be increased by another $10 \%$ if the system would use electrical storage, but the feasibility of electrical storage in residential buildings is questionable at the current state of technology. The currently described increasing of self-consumption in residential buildings does not save energy. The main effect comes from cost savings derived from decreased energy purchases from the electricity grid. Nearly zero energy buildings have to use technologies with high energy efficiency to achieve energy saving, but these aspects were not in the focus of this study. Modelling shows, that at an annual wind/solar energy mix of 70/30, doubling the preheating boiler volume from 80 to 160 litres adds extra $8 \%$ to the cover factor. A further upsizing does not bring additional benefits in terms of cost effectiveness, as the cover factor becomes ,saturated“, i.e. its increase slows down.

\section{ACKNOWLEDGEMENTS}

The Estonian Centre of Excellence in Zero Energy and Resource Efficient Smart Buildings supported this research and Districts, ZEBE, grant TK146 funded by the European Regional Development Fund.

\section{REFERENCES}

1. Aguilar, S., Souza, R.C., Pensanha, J.F. 2014. Predicting probabilistic wind power generation using nonparametric techniques. IEEE Conference Publications: 3th International Conference on Renewable Energy Research and Applications, pp. 709-712, Milwaukee. https://doi.org/10.1109/ICRERA.2014.7016477

2. Allik, A., Annuk, A. 2016. Autocorrelations of power output from small scale PV and wind power systems. IEEE Conference Publications: 2016 IEEE International Conference on Renewable Energy Research and Applications (ICRERA), pp. $279-284$. Birmingham, UK. https://doi.org/10.1109/ICRERA.2016.7884552

3. Allik, A., Märss, M., Uiga, J., Annuk, A. 2016. Optimization of the inverter size for grid-connected residential wind energy systems with peak shaving. Renewable Energy, Vol. 99, pp. 1116-1125. https://doi.org/10.1016/j.renene.2016.08.016

4. Annuk, A., Pikk, P., Kokin, E., Karapidakis, E. S., Tamm, T. 2011. Performance of wind-solar integrated grid connected energy system. Agronomy Research, Vol. 9(1-2), pp. 273-280.

5. Annuk, A., Allik, A., Pikk, P., Uiga, J., Tammoja, H., Toom, K., Olt, J. 2013. Increasing renewable fraction by smoothing consumer power charts in grid-connected wind-solar hybrid systems. Oil Shale, Vol. 30(2S), pp. $257-267$. https://doi.org/10.3176/oil.2013.2S.06

6. Annuk, A., Jõgi, E., Hovi, M., Märss, M., Uiga, J., Hõimoja, H., Peets, T., Kalder, J., Jasinskas, A., Allik, A. 2017. Increasing self electricity consumption by using double water heating boilers for residential net zero-energy buildings. IEEE Conference Publications: 2017 IEEE International Conference on Renewable Energy Research and Applications (ICRERA), pp. 1-6. San Diego, U.S. https://doi.org/10.1109/ICRERA.2017.8191249

7. Baetens, R., De Coninck, R., Van Roy, J., Verbruggen, B., Driesen, J., Helsen, L., Saelens, D. 2012. Assessing electrical bottlenecks at feeder level for residential net zero-energybuildings by integrated sy stem simulation. Applied Energy, Vol. 96, pp. 74-83. https://doi.org/10.1016/j.apenergy.2011.12.098

8. Caralis, G., Delikaraoglu, S., Zervos, A. 2011. Towards the optimum mix between wind and PV capacity in the Greek power system. European Wind Energy Conference \& Exhibition Scientific Proceedings, pp. 75-79.

9. Ciocan, A., Tazzrout, M., Prisecaru, T., Durastanti, J.-F. 2015. Thermodynamic evaluation for small scale compressed air energy storage system by integrating renewable energy resources. IEEE Conference Publications: 4th International Conference on Renewable Energy Research and Applications, pp. 455-1460, Palermo.

10. Circutor. M 7 Current transformers and shunts. Available at http://www.samey.is/vorur/Circutor/ M7_01_GB.pdf (accessed on 10/06/2017)

11. Civic Solar. Yingli Solar YL 245 P-29b 245W Poly SLV_WHT Solar Panel. Available at https://www.civicsolar.com/product/yingli-solar-yl-245-p-29b-245w-poly-slvwht-solar-panel (Accessed on 10/06/2017)

12. Elkinton, M.R., McGowan, J.G., Manwell, J.F. 2009. Wind power systems for zero net energy housing in the United States. Renewable Energy, Vol. 34, pp. 1270-1278. https://doi.org/10.1016/j.renene.2008.10.007

13. Ferrantelli, A., Ahmed, K., Pylsy, P., Kurnitski, J. 2017. Analytical modelling and prediction formulas for domestic hot water consumption in residential Finnish apartments. Energy and Buildings, Vol. 143, pp. 53-60. https://doi.org/10.1016/i.enbuild.2017.03.021

14. Gabbar, H.A., Abdelsalam, A.A. 2014. Microgrid energy management in grid connected and islanding modes based on SVC. Energy Conversion and Management, Vol. 86, pp. 964-972. https://doi.org/10.1016/j.enconman.2014.06.070

15. Hassanzadeh, M.N., Fotuhi.Firuzabad, M., Safdarian, A. 2017. Wind energy penetration with load shifting from the system wellbeing viewoint. International Journal of Renewable Energy Research-IJRER, Vol. 7(2), pp. 977-987.

16. Iqbal, M.T. 2004. A feasibility study of a zero energy home in Newfoundland. Renewable Energy, Vol. 29, pp. $277-289$. https://doi.org/10.1016/S0960-1481(03)00192-7 
17. Janitza electronics GmbH. Power Quality Analyser UMG 605 Operating manual and technical data. Available at https://www.janitza.com/manuals.html?file=files/download/manuals/current/UMG605/Janitza-Manual-UMG605-en.pdf (Accessed on 10/06/2017)

18. Kaldellis, J.K., Zafirakis, D. 2011. The wind energy (r)evolution: a short review of a long history. Renewable Energy, Vol. 36, pp. 1887-1901. https://doi.org/10.1016/j.renene.2011.01.002

19. Loh, P.C., Li, D., Chai, Y.K., Blaabjerg, F. 2013. Autonomous operation of hybrid microgrid with AC and DC subgrids. IEEE Transactions on Power Electronics, Vol. 28, pp. 2214-2223. https://doi.org/10.1109/TPEL.2012.2214792

20. Ming, T., Wang, Q., Peng, K., Cai, Z., Yang, W., Wu, Y., Cong, T. 2015. The influence of non-uniform high heat flux on thermal stress of thermoelectric power generator. Energies, Vol. 8, pp. 12584-12602. https://doi.org/10.3390/en81112332

21. Pourmousavi, S.A., Patrick, S.N., Nehrir, M.H. 2014. Real-time demand response through aggregate electric water heaters for load shifting and balancing wind generation. IEEE Transactions on Smart Grid, Vol. 5(2), pp. $769-778$. https://doi.org/10.1109/TSG.2013.2290084

22. Rahmoun, A., Armstorfer, A., Helguero, J., Biechl, H., Rosin, A. 2016. Mathematical Modeling and Dynamic Behavior of a Lithium-Ion Battery System for Microgrid Application. IEEE International Energy Conference (ENERGYCON), pp. 1-6, Leuwen, Belgium. https://doi.org/10.1109/ENERGYCON.2016.7513977

23. Rosin, A., Palu, I., Rosin, K., Auvaart, A. 2012. Dimensioning of Electricity Storage according to Small Wind Turbine Power Generation and Household Load Patterns. 38th Annual Conference on IEEE-Industrial-Electronics-Society (IECON ), pp. 5173-5178, Montreal.

24. SMA.2012. Sunny Boy 3000TL / 4000TL / 5000TL. Available at http://files.sma.de/d1/5692/SB5000TL-DDE112440W.pdf (Accessed on 10/06/2017)

25. Sonkyo Energy. Windspot $3.5 \mathrm{Kw}$. Available at http://usa.windspot.es/home-wind-turbines/products/89/windspot-35-kw (Accessed on 10/06/2017)

26. Zoss, T., Karklina I., Blumberga, D. 2016. Power to gas and pumped hydro storage potential in Latvia. Energy Procedia, Vol. 95 , pp. 528-535. https://doi.org/10.1016/j.egypro.2016.09.080

27. Tabone, M.D., Callaway, D.S. 2014. Modeling variability and uncertainty of photovoltaic generation: A hidden state spatial statistical approach. IEEE Transactions on Power Systems, Vol. 30, pp. 2965-2973. https://doi.org/10.1109/TPWRS.2014.2372751

28. Vanhoudt, D., Geysen, D., Claessens, B., Leemans, B., Jespers, L., Van Bael, J. 2014. An actively controlled residential heat pump: potential on peak shaving and maximization of self-consumption of renewable energy. Renewable Energy, Vol. 63, pp. 531-543. https://doi.org/10.1016/j.renene.2013.10.021

29. World Energy Council. Electricity use per household. Electricity Consumption Efficiency 2015. Available at https://wecindicators.enerdata.net/household-electricity-use.html (Accessed on 10/06/2017) 